\title{
Eksplorasi etnomatematika pada Masjid Jami' Al-Baitul Amien Jember
}

\author{
Erfan Yudianto*, Rizka Amalia Febriyanti, Sunardi Sunardi, Titik Sugiarti, Mutrofin \\ Mutrofin \\ Fakultas Keguruan dan Ilmu Pendidikan, Universitas Jember \\ * Corresponding Author. E-mail: erfanyudi@unej.ac.id
}

Submitted: 6 Desenber 2020 | Revised: 30 Maret 2021 | Accepted: 30 Maret 2021 | Available Online: 12 April 2021

\begin{abstract}
Abstrak
Tujuan penelitan ini adalah untuk menggali etnomatematika pada bangunan Masjid Jami’ Al-Baitul Amien Jember yang kemudian digunakan sebagai bahan untuk membuat paket tes matematika bagi siswa. Penelitian ini merupakan penelitian kualitatif dengan pendekatan etnografi. Metode pengumpulan data yang digunakan adalah observasi dan wawancara. Subjek penelitian yaitu tiga observer dan dua narasumber yakni pengurus Yayasan Masjid Jami’ Al-Baitul Amien Jember. Satu orang merupakan ketua pengurus yang paham tentang sejarah Masjid Jami' Al-Baitul Amien dan satu orang merupakan satu-satunya pengurus yang mengikuti masa pembangunan sehingga mengerti terhadap struktur bangunan masjid. Hasil penelitian menunjukkan bahwa pada bagian-bagian bangunan Masjid Jami’ Al-Baitul Amien Jember terdapat konsep-konsep matematika. Bagian-bagian bangunan yang dimaksud yaitu kubah masjid, tiang penyangga masjid, lantai dua, dinding pancuran Ruang Wudlu, dan menara masjid. Konsep-konsep matematika yang muncul adalah bangun datar, bangun ruang, kekongruenan, dan refleksi.
\end{abstract}

Kata Kunci: etnomatematika, Masjid Jami 'Al-Baitul Amien Jember, paket tes matematika

\section{Ethnomathematics exploration at the Jami 'Al-Baitul Amien Jember Mosque}

\begin{abstract}
The purpose of this research is to explore ethnomathematics at the Jami 'Al-Baitul Amien Jember Mosque building which is then used as material to design mathematics test packages for students. This research was a qualitative study with an ethnographic approach. The data collection methods used were observations and interviews. The research subjects were three observers and two resource persons, namely the management of the Jami 'Al-Baitul Amien Jember Mosque Foundation. One person is the chairman of the committee who understands the history of the Jami 'Al-Baitul Amien Mosque and one person is the only administrator who followed the construction period so that he understands the structure of the mosque building. The results show that the parts of the Jami 'AlBaitul Amien Jember Mosque have mathematical concepts. The building parts meant are the dome of the mosque, the pillars of the mosque, the second floor, the shower wall of the Wudlu Room, and the mosque tower. Mathematical concepts that emerge are $2 D$ shapes, $3 D$ shapes, congruence, and reflection.
\end{abstract}

Keywords: ethnomathematics, Jami 'Al-Baitul Amien Jember Mosque, mathematics test package

How to cite:

Yudianto, E., Febriyanti, R. A., Sunardi, S., Sugiarti, T., \& Mutrofin, M. (2021). Eksplorasi etnomatematika pada Masjid Jami' Al-Baitul Amien Jember. Ethnomathematics Journal, 2(1), 11-20. https://doi.org/10.21831/ej.v2i1.36329

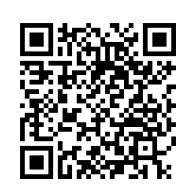




\section{PENDAHULUAN}

Pendidikan memiliki peran penting bagi kehidupan manusia dan negara, karena perkembangan zaman yang terus berkembang. Salah satu mata pelajaran yang dapat menunjang kemajuan pendidikan adalah matematika. Pemberian mata pelajaran matematika ini dimaksudkan untuk mengajarkan dan membekali peserta didik untuk berpikir logis, kritis, sistematis, kreatif, dan analitis. Untuk mencapai tujuan-tujuan tersebut tidaklah mudah karena matematika masih sering dianggap sebagai mata pelajaran yang sulit oleh siswa dan ditakuti (Sunardi \& Yudianto, 2016; Sunardi et al., 2019; Yudianto, 2015). Permasalahan lainnya adalah pengajaran matematika di sekolah masih cenderung kaku, sering sebatas pada hafalan dan hanya berbicara tentang angka dan rumus. Proses pembelajaran yang kurang terkait dengan kehidupan sehari-hari (hanya fokus pada pemecahan soal-soal bukan masalah) juga menyebabkan peserta didik mengalami kesulitan untuk mengaplikasikan pembelajaran matematika dalam kehidupan sehari-harinya (Evi, 2011). Salah satu cara yang dapat menunjang kebermaknaan pembelajaran matematika yaitu melalui pembelajaran yang berkaitan dengan kearifan lokal (local wisdom) atau belajar dari kebiasaan (budaya) yang sering dilakukan di kehidupan sehari-hari siswa.

Konteks budaya dapat merangsang pengetahuan peserta didik agar dapat mudah diingat dan peserta didik juga dapat menghubungkan langsung dengan kehidupan sehari-harinya (Rohaeti, 2011). Bentuk integrasi dari matematika dengan kebudayaan tersebut kemudian dikenal dengan istilah etnomatematika (Aprillianti, Sunardi, \& Yudianto, 2019; Khofifah, Sugiarti, \& Setiawan, 2018; MacDonald et al., 2016; Mauluah \& Marsigit, 2019; Son, 2017). Etnomatematika merupakan pembelajaran matematika yang mengangkat tema-tema budaya lokal secara konseptual, termasuk kebiasaan yang dilakukan oleh peserta didik atau masyarakat di sekitar mereka. Dari sini peserta didik diajak memahami dan menerapkan jika keberadaan matematika bukan saja hanya berada dalam lingkup kelas dan sekolah saja, melainkan juga terdapat di lingkungan sekitar dan kehidupan sehariharinya. Etnomatematika diterapkan sebagai sarana untuk memotivasi, menstimulasi, mengatasi kejenuhan peserta didik serta memberikan nuansa yang baru pada pembelajaran matematika (Sirate, 2012). Objek kebudayaan yang kehadirannya dekat dengan kehidupan sehari-hari peserta didik diperlukan sebagai upaya untuk mewujudkan hal tersebut. Salah satu objek kebudayaan yang sangat dekat dengan kehidupan peserta didik adalah masjid.

Masjid dipilih sebagai objek kebudayaan atas dasar tema pengembangan kurikulum 2013 yang menginginkan adanya pembentukan karakter dan juga sikap ketaqwaan peserta didik kepada Tuhan Yang Maha Esa. Diharapkan dengan menelusuri sejarah tempat ibadah yang terdapat pada daerah pada masing-masing siswa, siswa dapat membangun nilai-nilai kehidupan beragamanya. Selain sebagai tempat ibadah umat Islam, masjid juga merupakan pusat seni budaya Islam yang bernafaskan kebangsaan masing-masing, sehingga bangunannya merupakan kelompok bangunan monumental, arsitektur Islam, dan karakteristik daerah dimana masjid itu dibangun (Marli, 2017).

Penelitian mengenai etnomatematika pada bangunan masjid sebelumnya telah dilakukan oleh beberapa peneliti. Salah satunya adalah penemuan adanya beberapa aspek matematika pada Masjid Agung di Yogyakarta (Putri, 2017; Rohayati, Karno, \& Chomariyah, 2017). Sebagai upaya pembaharuan, penelitian kali ini ditujukan untuk menggali etnomatematika pada Masjid Jami’ AlBaitul Amien Jember. Masjid Jami' Al-Baitul Amien merupakan salah satu masjid kebanggaan Kabupaten Jember yang letaknya berada di pusat kota dan memiliki bentuk yang unik, artistik, dan berbeda dengan masjid pada umumnya. Masjid Jami' Al-Baitul Amien Jember memiliki konsep bundar dan melengkung pada bangunannya. Konsep ini dipilih dengan mengadopsi gaya bangunanbangunan masjid di Mesir dan Persia. Bentuk dan arsitektur Masjid Jami’ Al-Baitul Amien Jember perlu digali untuk menemukan nilai-nilai etnomatematika didalamnya, yang kemudian dapat digunakan dalam proses pembelajaran matematika yang lebih realistis. Berdasarkan latar belakang masalah tersebut, tujuan dari penelitian ini adalah untuk menggali konsep-konsep apa saja yang terdapat pada bangunan Masjid Jami' Al-Baitul Amien Jember dan menggunakan hasil penelitian ini sebagai bahan untuk membuat paket tes peserta didik kelas VI sekolah dasar. 


\section{METODE}

Penelitian ini menggunakan metode kualitatif dengan pendekatan etnografi. Pendidikan kualitatif merupakan suatu prosedur penelitian yang menghasilkan data berbentuk deskriptif dari segala bentuk ucapan, tulisan maupun gambaran dari objek dan subjek yang diamati (Miles \& Huberman, 2009; Sugiyono, 2013). Penelitian menggunakan etnografi adalah usaha untuk menggambarkan, menjelaskan, dan juga menganalisis segala unsur kebudayaan yang ada dalam masyarakat (Zayyadi, 2017). Metode pengumpulan data yang digunakan adalah observasi, wawancara, dan dokumentasi. Observasi dilaksanakan pada 7 April 2020 dan bertempat di Masjid Jami' Al-Baitul Amien yang beralamat di Jalan Raya Sultan Agung, Jember Lor, Kecamatan Patrang, Kabupaten Jember, Jawa Timur. Observasi dilaksanakan bersamaan dengan pendokumentasian objek-objek yang dilihat dan ditemui kemudian mengklasifikasikan dalam bentuk konsep-konsep matematika. Setelah dirasa cukup, maka pada waktu yang telah disepakati yaitu pada 8 April 2020, dilaksanakan wawancara kepada subjek. Subjek penelitian ini adalah dua orang pengurus Yayasan Masjid Jami' Al-Baitul Amien Jember, ketua pengurus yang paham tentang sejarah masjid (S1), dan satu pengurus yang mengetahui dengan baik atau memahami struktur masjid (S2). Wawancara dilaksanakan secara bergantian di aula masjid dengan menggunakan alat perekam (audio visual).

Tahapan penelitian dimulai dengan memilih topik dan menentukan fokus penelitian, setelah itu membuat pedoman observasi dan pedoman wawancara yang juga diuji keabsahannya oleh dua orang validator yaitu dua dosen pendidikan matematika Universitas Jember dan diperoleh skor validasi sebesar 4,5 dengan kategori sangat valid skala 5 untuk pedoman obeservasi dan pedoman wawancara. Tahap pengumpulan data dilakukan dengan melakukan observasi terhadap objek penelitian dan melakukan wawancara dengan subjek penelitian. Data yang telah diperoleh dari hasil observasi, wawancara, dan dokumentasi kemudian direduksi, dianalisis, dan kemudian disusun secara sistematis.

\section{HASIL DAN PEMBAHASAN}

Berdasarkan hasil pengumpulan data, diperoleh hasil bahwa terdapat nilai-nilai etnomatematika pada beberapa bagian bangunan Masjid Jami' Al-Baitul Amien Jember. Bagianbagian bangunan masjid tersebut yaitu: 1.) Kubah masjid; 2.) Tiang penyangga masjid; 3.) Lantai dua masjid; 4.) Dinding pancuran masjid; dan 5.) Menara masjid.

\section{Kubah Masjid}

Kubah pada Masjid Jami’ Al-Baitul Amien Jember berbentuk bola terpancung yang hampir menutupi badan bangunan. Pembuatan kubah bebas, namun gaya kubah pada masjid ini diadaptasi dari bentuk bundar gaya masjid-masjid yang terdapat di Mesir dan Persia. Bangunan masjid terdiri dari 2 bangunan pendukung (ruang wudlu) dan 5 bangunan utama. 5 bangunan utama tersebut memiliki filosofi dari jumlah sholat fardhu dan jumlah rukun Islam. Kemudian untuk total keseluruhan bangunan terdapat 7 bangunan dengan filosofi yang beragam. Tujuh bangunan tersebut menggambarkan Allah menciptakan 7 lapisan langit dan bumi, kemudian 7 hari dalam seminggu, bacaan bismillah 7 kali, dan Qul huwallah 7 kali. Ukuran antara kubah ruang sholat utama, kubah ruang sholat sedang, kubah ruang sholat kecil, dan kubah ruang wudlu berbeda. Semakin ke arah luar, ukuran kubah semakin mengecil dengan alasan estetika. Ukuran diameter kubah ruang sholat utama adalah sebsear $34 \mathrm{~m}$ dengan ketinggian puncak kubah setinggi 14,585 m. Ukuran diameter kubah ruang sholat sedang (kanan dan kiri) memiliki luas sebesar $20 \mathrm{~m}$ dengan ketinggian puncak kubah 8,43 m. Ukuran diameter kubah ruang sholat kecil (kanan dan kiri) sebesar $11 \mathrm{~m}$ dengan ketinggian puncak kubah setinggi 5,95 m. Ukuran diameter kubah ruang wudlu (kanan dan kiri) sebesar 8 m dengan ketinggian puncak kubah setinggi 4,22 m. Bentuk kubah pada Masjid Jami' AlBaitul Amien Jember dapat dilihat pada Gambar 1. 


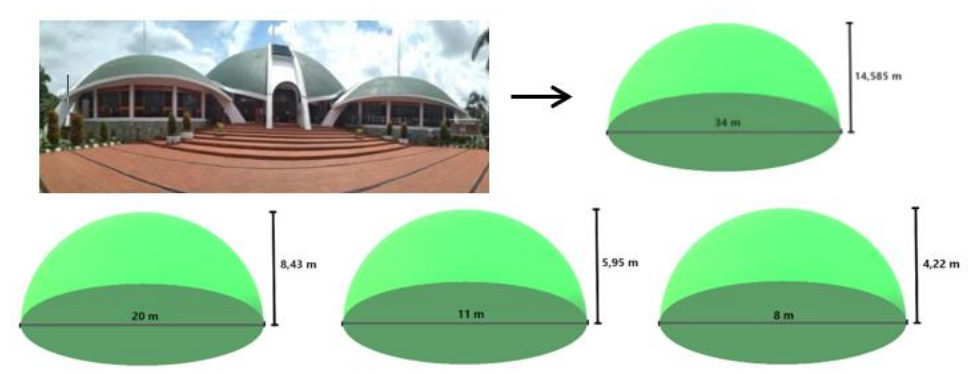

(a) Tampak dari depan

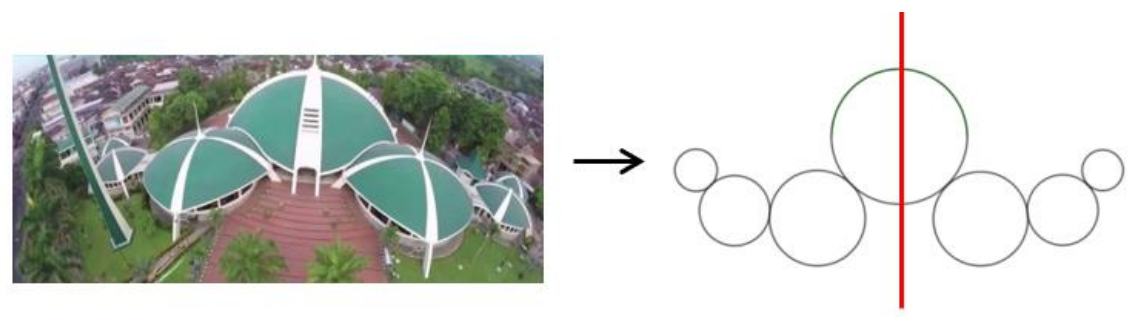

(b) Tampak dari atas

Gambar 1. Bentuk Kubah

Berikut ini cuplikan wawancara dengan S1 mengenai kubah

P4004: Mengapa kubah masjid dibuat dengan bentuk demikian pak?

S4004: Masjid ini kan hasil arsitektur Yaying Keyser. Beliau menggunakan konsep bundar yang diambil dari bangunan-bangunan masjid di Mesir dan Turki. Kemudian sebetulnya bentuk masjid itu dibuat berjalin bergelindang. Nah dengan bentuk yang begitu seandainya ada bencana gempa besar misalnya, maka masjid mungkin hanya akan menggelinding saja karena bentuknya.

P4005: Apakah ada aturan khusus dalam membuat bentuk kubah masjid atau dapat dibuat bebas pak?

S4005: Tidak ada sebenarnya , hanya sesuai arsitektur saja. Arsitek kan menginginkan sesuatu yang unik, sesuatu yang beda dari yang lain.

P4006: Mengapa dipilih sejumlah 7 kubah bapak?

S4006: Ya, jadi kan memang bangunan masjid terdiri dari 2 bangunan pendukung (ruang wudlu) dan 5 bangunan utama. 5 bangunan utama ini filosofinya adalah jumlah sholat fardhu dan jumlah rukun Islam. Kemudian untuk total keseluruhan bangunan ada 7, filosofinya banyak. Menggambarkan Allah menciptakan 7 lapisan langit dan bumi, kemudian 7 hari dalam seminggu, bacaan bismillah 7 kali dan Qul huwallah 7 kali.

P4007: Mengapa penempatan kubah-kubah masjid seperti tersebut pak?

S4007: Agar artistik saja , agar terlihat lebih menarik.

Berikut ini cuplikan wawancara dengan S2 mengenai kubah

P5001: Bagaimana ukuran masing-masing kubah bapak?

S5001: Ukuran bangunannya berbeda-beda. Ruang sholat utama tinggi puncaknya $14,585 \mathrm{~m}$ dan berdiameter $34 \mathrm{~m}$. Ruang Sholat Sedang kanan dan kiri tingginya $8,43 \mathrm{~m}$ dan berdiameter $20 \mathrm{~m}$. Ruang sholat kecil kanan dan kiri tinggi puncaknya 5,95 m dan berdiameter $11 \mathrm{~m}$. Ruang wudlu kanan dan kiri tinggi puncaknya $4,22 \mathrm{~m}$ an berdiameter $8 \mathrm{~m}$.

P5002: Bagaimana cara membuat kubah masjid sehingga tampak membentuk sebuah bangunan yang teratur bapak?

S5002: Ya itu kan dibuat pondasinya dulu, dicor, dibentuk sesuai desain dari arsitek. Pembangunannya dilakukan dalam waktu bersamaan tetapi urutan pengerjaan dan pondasinya sama sehingga bangunan seperti ruang sholat sedang, ruang sholat kecil, dan tempat wudlu yang kanan maupun kiri itu sama. Ukuran dan penempatannya juga sesuai arsiteknya.

\section{Tiang Penyangga}

Tiang penyangga lantai 2 pada Masjid Jami’ Al-Baitul Amien Jember memiliki bentuk bangun ruang yaitu tabung. Bentuk tabung dipilih karena sesuai dengan konsep masjid yaitu 
melingkar. Tiang penyangga yang berjumlah 17 memiliki banyak makna didalamnya, yaitu 17 rakaat dalam sholat fardhu, tanggal 17 Ramadhan adalah waktu turunnya Al-Qur'an, dan tanggal 17 adalah tanggal kemerdekaan Republik Indonesia. Setiap tiang penyangga memiliki tinggi sekitar $6 \mathrm{~m}$ dan keliling sebesar $206 \mathrm{~cm}$. Tiang penyangga di lantai 2 pada Masjid Jami’ Al-Baitul Amien Jember dapat dilihat pada Gambar 2.

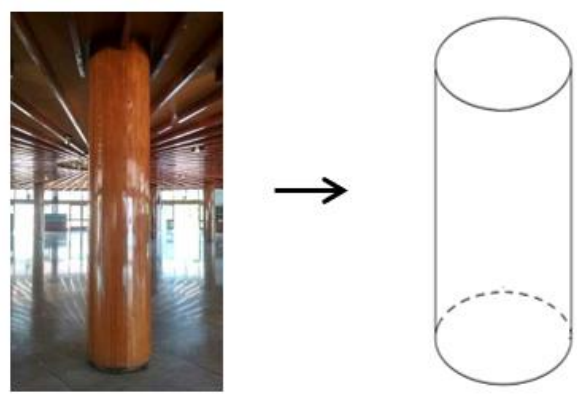

Gambar 2. Tiang Penyangga

Berikut ini cuplikan wawancara dengan S1 mengenai tiang penyangga

P4013: Mengapa tiang penyangga dibuat dengan bentuk demikian pak?

S4013: Sesuai dengan konsep masjid tadi , melingkar. Sehingga tiang penyangganya berbentuk tabung bukan balok.

P4014: Mengapa tiang penyangga dibuat sejumlah tersebut?

S4014: Nah tiang masjid ini jumlahnya ada 17 yang memang punya banyak makna, yaitu 17 rakaat dalam sholat fardhu, tanggal 17 Ramadhan waktu turunnya Al-Qur'an, dan tanggal 17 kemerdekaan Republik Indonesia.

P4015: Apakah tiang penyangga harus dibuat dalam bentuk dan jumlah seperti tersebut bapak?

S4015: Tidak harus , tergantung arsitektur dan makna yang ingin diselipkan.

Berikut ini cuplikan wawancara dengan S2 mengenai tiang penyangga

P5006: Bagaimana ukuran masing-masing tiang penyangga bapak?

S5006: Kalau diameter lingkarnya saya belum mengukur , tapi untuk tingginya sekitar 6 meteran.

P5007: Bagaimana cara membuat tiang penyangga sehingga tampak membentuk sebuah bangun yang teratur pak?

S5007: Tiang penyangga itu dibuatnya sama seperti tiang biasanya , dicor dalam ukuran yang sama.

\section{Lantai 2 Masjid}

Lantai 2 Masjid Jami’ Al-Baitul Amien Jember memiliki bentuk bangun ruang yaitu tabung. Bentuk yang melingkar ini dipilih untuk menyesuaikan bentuk bangunan yang berbentuk bola terpancung dan menambah kesan estetik. Ukuran lantai 2 juga disesuaikan dengan ukuran ruang sholat utama yang berdiameter sebesar $23 \mathrm{~m}$. Di bagian bawah lantai 2 dipasang kayu-kayu yang berfungsi untuk menopang bangunan dan menambah nilai estetika pada bangunan masjid, sehingga walaupun Masjid Jami' Al-Baitul Amien Jember memiliki gaya arsitektur seperti masjid-masjid di Timur Tengah, namun tetap memiliki unsur tradisional dan berciri khas Indonesia didalamnya. Lantai 2 pada Masjid Jami’ Al-Baitul Amien Jember dapat dilihat pada Gambar 3.
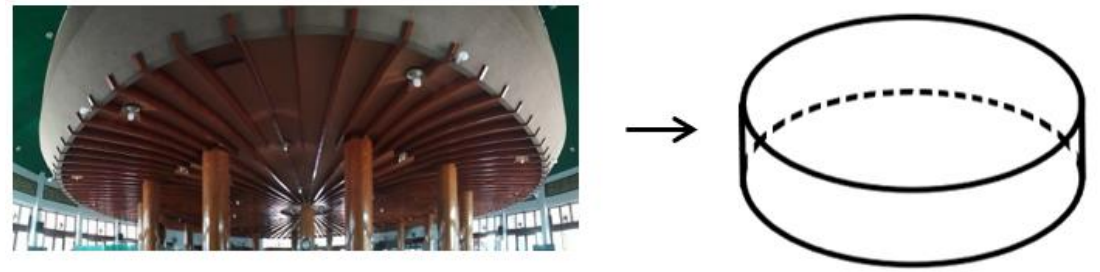

Gambar 3. Lantai 2 Masjid Jami’ Al-Baitul Amien Jember 
Berikut ini cuplikan wawancara dengan S1 mengenai lantai 2

P4012: Mengapa lantai 2 pada ruang utama dibuat dengan bentuk demikian bapak?

S4012: Lantai 2 ruang utama dibentuk melingkar tentu karena menyesuaikan bentuk bangunan utamanya, agar sesuai saja. Selain itu juga kembali lagi ke alasan estetika.

Berikut ini cuplikan wawancara dengan S2 mengenai lantai 2

P5004: Bagaimana ukuran lantai 2 di ruang utama pak?

S5004: Lantai 2 itu pastinya disesuaikan dengan ukuran bangunan ruang sholat utama , diameternya 23 $\mathrm{m}$.

P5005: Bagaimana cara membuat lantai 2 di ruang utama sehingga tampak membentuk sebuah bangun yang teratur?

S5005: Sama juga seperti tadi. Dicor dulu , kemudian dibuat dalam bentuk lingkaran. Di bagian bawah lantai 2 itu dipasang kayu-kayu yang selain fungsinya untuk menopang bangunan juga untuk estetika. Sehingga walaupun masjid ini gaya arsitekturnya seperti masjid-masjid di Timur Tengah namun tetap ada unsur tradisionalnya.

\section{Dinding Pancuran Ruang Wudlu Masjid}

Ruang wudlu pada Masjid Jami' Al-Baitul Amien Jember memiliki bentuk yang sama seperti ruang-ruang sholat yang lain, namun terdapat perbedaan pada bagian tengah ruangan yaitu bagian dinding pancuran. Bagian tersebut memiliki bentuk gabungan dari kerucut terpancung dan tabung. Ruang wudlu dibuat dengan bentuk demikian untuk alasan estetika. Pancuran air terdapat di sekeliling dinding untuk memaksimalkan jumlah jamaah yang mengambil wudhu dalam satu ruangan. Selain itu di bagian tengahnya juga terdapat pancuran air. Dinding pancurang ruang wudlu pada Masjid Jami’ Al-Baitul Amien Jember dapat dilihat pada Gambar 4.

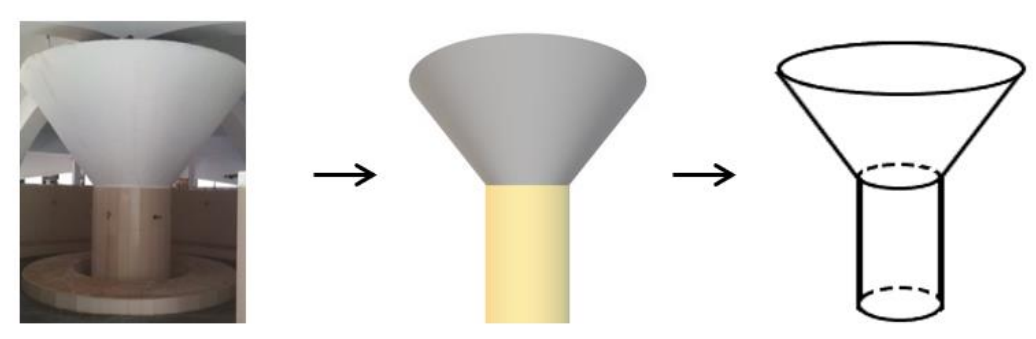

Gambar 4. Dinding pancuran Ruang Wudlu

Berikut ini cuplikan wawancara dengan S1 mengenai Ruang Wudlu

P4010: Mengapa ruang wudlu dibuat dengan bentuk demikian?

S4010: Kembali lagi ke alasan estetika. Pancuran air ada di sekeliling dinding untuk memaksimalkan jumlah jamaah yang mengambil wudhu dalam satu ruangan. Kemudian di bagian tengahnya juga terdapat pancuran air.

P4011: Apakah ada aturan khusus dalam membuat bentuk ruang wudlu masjid atau dapat dibuat bebas?

S4011: Bebas saja sebenarnya, yang penting dipisah antara ruang wudlu laki-laki dan ruang wudlu perempuan.

Berikut ini cuplikan wawancara dengan S2 mengenai Ruang Wudlu

P5003: Bagaimana cara membuat ruang wudlu sehingga tampak membentuk sebuah bangun yang teratur?

S5003: Sama seperti bangunan yang lain. Dibuat pondasi terlebih dahulu, dicor, dan dibangun membentuk desain dari arsiteknya. 


\section{Menara Masjid}

Menara Masjid Jami' Al-Baitul Amien Jember memiliki bentuk limas segi lima terpancung dan bola terpancung. Bentuk limas segi lima terpancung terdapat pada badan menara, sedangkan bentuk bola terpancung terdapat pada kubah di atas menara. Menara pada masjid dilengkapi dengan pengeras suara pada bagian atas yang berfungsi untuk mengumandangkan panggilan sholat. Tinggi menara sampai dengan penangkal petir adalah $32,90 \mathrm{~m}$. Bentuk dan nilai matematis pada menara Masjid Jami’ Al-Baitul Amien Jember dapat dilihat pada Gambar 5.
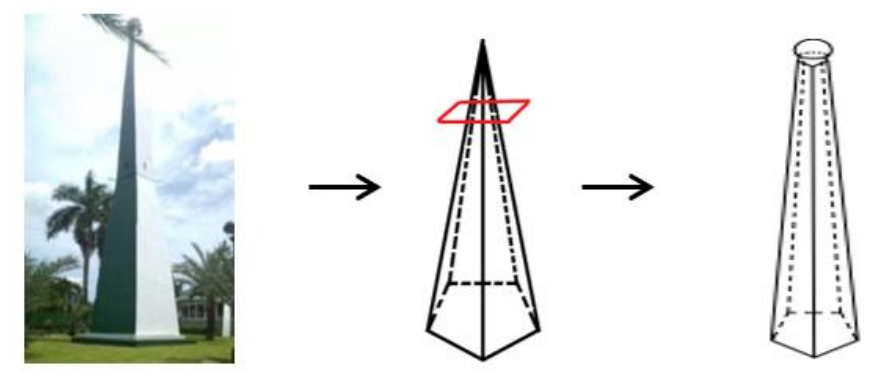

Gambar 5. Menara Masjid Jami’ Al-Baitul Amien Jember

Berikut ini cuplikan wawancara dengan S2 mengenai menara masjid

P5012: Bagaimana dengan ukuran menara masjid bapak?

S5012: Untuk ukuran yang mendetail saya kurang tau ya, namun tinggi menara sampai dengan penangkal petir itu $32,90 \mathrm{~m}$.

Dibalik makna dan filosofi yang terkandung dalam bentuk bangunan Masjid Jami’ Al-Baitul Amien Jember, dapat diketahui pula bahwa pada Masjid Jami' Al-Baitul Amien Jember terdapat konsep-konsep matematika. Konsep-konsep matematika tersebut yaitu: bangun datar, bangun ruang, kekongruenan, dan refleksi.

\section{Kubah Masjid}

Berdasarkan hasil analisis data, diperoleh data ukuran diameter kubah ruang sholat utama sebesar $34 \mathrm{~m}$ dengan ketinggian puncak kubah setinggi 14,585 m. Ukuran diameter kubah ruang sholat sedang (kanan dan kiri) sebesar $20 \mathrm{~m}$ dengan ketinggian puncak kubah setinggi 8,43 m. Ukuran diameter kubah ruang sholat kecil (kanan dan kiri) sebesar $11 \mathrm{~m}$ dengan ketinggian puncak kubah setinggi 5,95 m. Ukuran diameter kubah ruang wudlu (kanan dan kiri) sebesar $8 \mathrm{~m}$ dengan ketinggian puncak kubah setinggi 4,22 m. Data tersebut menunjukkan bahwa kubah Masjid Jami' Al-Baitul Amien Jember tidak berbentuk setengah bola seperti julukan masyarakat, melainkan berbentuk bola terpancung karena ukuran tinggi seluruh kubah di Masid Jami' Al-Baitul Amien Jember tidak tepat setengah dari ukuran diameter kubah. Hal ini juga meunjukkan bahwa kubah Masjid Jami’ Al-Baitul Amien Jember memiliki konsep bangun ruang bola terpancung.

Bola terpancung adalah bola yang dipotong oleh sebuah bidang, sehingga bola menjadi terpotong dan tidak utuh. Adanya konsep bola terpancung ini juga mengakibatkan munculnya konsep bangun datar lingkaran. Konsep kekongruenan muncul pada persamaan bentuk dan ukuran kubah ruang sholat sedang sebelah kanan dan kiri, kubah ruang sholat kecil sebelah kanan dan kiri, serta ruang wudlu sebelah kanan dan kiri. konsep refleksi juga terlihat dari persamaan bentuk dan ukuran kubah di sisi kanan dan sisi kiri (meliputi ruang sholat sedang, ruang sholat kecil dan ruang wudlu). Berdasarkan hasil penelitian, dapat diketahui bahwa kubah Masjid Jami' Al-Baitul Amien Jember memiliki konsep bangun ruang, bangun datar, kekongruenan, dan refleksi. 


\section{Tiang Penyangga Masjid}

Berdasarkan hasil analisis data, diperoleh data bahwa tiang penyangga pada Masjid Jami' Al-Baitul Amien Jember berjumlah 17 dengan bentuk dan ukuran yang sama. Salah satu tiang berada di bawah pusat lantai 2, sedangkan 16 tiang yang lain tersebar di bagian bawah lantai 2 dengan jarak yang sama. Pada tiang penyangga lantai 2 Masjid Jami' Al-Baitul Amien Jember ditemukan konsep bangun ruang dan kekongruenan. Konsep bangun ruang yang ditemukan yaitu tabung. Konsep kekongruenan ditemukan pada kesamaan ukuran setiap tiang penyangga.

\section{Lantai 2 Masjid}

Berdasarkan hasil analisis data, diperoleh hasil bahwa pada lantai 2 ditemukan konsep bangun ruang dan bangun datar. Konsep bangun ruang yang ditemukan yaitu tabung, sedangkan konsep bangun datar yang ditemukan adalah lingkaran.

\section{Dinding Pancuran Ruang Wudlu}

Berdasarkan hasil analisis data, pada dinding pancuran ruang wudlu ditemukan beberapa konsep bangun ruang. Konsep bangun ruang yang ditemukan yaitu kerucut terpancung dan tabung. Bagian yang berbentuk kerucut terpancung adalah penyangga dinding bagian atas. Kerucut terpancung adalah kerucut yang dipotong oleh sebuah bidang, sehingga kerucut menjadi terpotong dan tidak utuh. Kemudian bagian yang berbentuk tabung adalah dinding tempat menempelnya keran air. Kerucut terpancung berada di atas, posisinya terbalik dengan bagian kerucut terpancung yang terpotong menempel tepat dengan tabung dibawahnya karena memiliki ukuran diameter yang sama dengan diameter tabung.

\section{Menara Masjid}

Berdasarkan hasil analisis data, pada menara Masjid Jami’ Al-Baitul Amien Jember terdapat konsep bangun ruang dan bangun datar. Konsep bangun ruang yang ditemukan yaitu limas segi lima terpancung dan bola terpancung. Bagian yang berbentuk limas segi lima terpancung terdapat pada badan menara. Limas segi lima terpancung adalah sebuah limas segi lima yang dipotong oleh sebuah bidang sehingga limas segi lima menjadi tidak utuh. Bentuk limas segi lima terpancung ini memunculkan adanya konsep bangun datar trapesium. Bentuk bola terpacung terdapat pada kubah di atas menara.

Konsep-konsep matematika yang ditemukan pada bangunan Masjid Jami' Al-Baitul Amien Jember ini adalah materi bangun datar, bangun ruang, dan kekongruenan refleksi yaitu menghitung luas dan keliling lingkaran, luas trapesium, luas selimut tabung, dan menentukan hasil refleksi. Soal dan penjelasan dibuat berdasarkan identifikasi etnomatematika pada bentuk bangunan Masjid Jami' Al-Baitul Amien Jember. Hal ini sejalan dengan hasil penelitian yang dilakukan oleh Rohayati, Karno, dan Chomariyah (2017) yang mengatakan bahwa unsur-unsur matematika sering dan hampir ditemui disetiap sudut bangunan masjid. Menurut Bakhrodin, Istiqomah, dan Abdullah (2019) hasil yang diperoleh dari identifikasi Masjid Mataram Kota Gede adalah ukiran-ukiran (ornamen) pada dinding, bangunan pendopo, atap masjid, beduk yang erat kaitanya dengan konsep geometri diantaranya bagun datar dan bangun ruang. Kemudian hasil penelitian Putra, Wijayanto, dan Widodo (2020) menjelaskan bahwa konsep matematika yang muncul pada masjid soko tunggal berupa segitiga, persegi, persegipanjang, belah ketupat, lingkaran dan refleksi. Hal ini menjelaskan bahwa sebenarnya matematika erat kaitannya dengan kehidupan sehari-hari siswa atau masyarakat, sehingga bukan hal yang sulit sebenarnya dalam belajar matematika jika cara menyajikan konsepkonsep matematika dengan tepat. 


\section{SIMPULAN}

Berdasarkan hasi dan pembahasan sebelumnya dapat disimpulkan bahwa terdapat nilai-nilai etnomatematika pada Masjid Jami’ Al-Baitul Amien Jember. Etnomatematika muncul pada bentuk bagian-bagian bangunan masjid. Bagian-bagian masjid tersebut ialah kubah masjid, tiang penyangga, lantai 2 masjid, dinding pancuran ruang wudlu, dan menara masjid. Konsep-konsep matematika yang ditemukan ialah bangun datar (lingkaran dan trapesium), bangun ruang (bola terpancung, tabung, kerucut terpancung, dan limas segi lima terpancung), kekongruenan, dan refleksi. Hasil dari penelitian ini akan dibuat paket tes siswa untuk kelas VI Sekolah Dasar yang berkenaan dengan etnomatematika Masjid Jami’ Al-Baitul Amien Jember. Berdasarkan penelitian yang telah dilakukan, saran untuk penelitian selanjutnya adalah menggali lebih dalam konsep-konsep matematika yang terdapat pada bangunan Masjid Jami' Al-Baitul Amien Jember maupun bangunan masjid yang lain untuk mendapatkan cakupan materi yang lebih luas dan menggunakan unsur etnomatematika yang telah diperoleh dalam penelitian ini sebagai acuan pengembangan bahan ajar siswa.

\section{DAFTAR PUSTAKA}

Aprillianti, I., Sunardi, S., \& Yudianto, E. (2019). Etnomatematika pada aktivitas petani kakao desa temuasri sempu banyuwangi sebagai bahan ajar siswa. Saintifika: Jurnal Ilmu Pendidikan MIPA Dan MIPA, 21(1), 1-18. https://doi.org/https://doi.org/10.19184/saintifika.v21i1.9715

Bakhrodin, B., Istiqomah, U., \& Abdullah, A. A. (2019). Identifikasi etnomatematika pada Masjid Mataram Kotagede Yogyakarta. Jurnal Ilmiah Soulmath: Jurnal Edukasi Pendidikan Matematika, 7(2), 113-124. https://doi.org/10.25139/smj.v7i2.1921

Evi, S. (2011). Pendekatan Matematika Realistik (PMR) untuk meningkatkan kemampuan berfikir siswa di tingkat sekolah dasar. METODIK DIDAKTIK: Jurnal Pendidikan Ke-SD-An, 2(2), 79 85. Retrieved from http://jurnal.upi.edu/md/view/670/pendekatan-matematika-realistik-(pmr)untuk-meningkatkan-kemampuan-berfikir-siswa-di-tingkat-sekolah-dasar.html

Khofifah, L., Sugiarti, T., \& Setiawan, T. B. (2018). Etnomatematika karya seni batik khas Suku Osing Banyuwangi sebagai bahan Lembar Kerja Siswa Materi Geometri Transformasi. KADIKMA, 9(3), 148-159. https://doi.org/10.19184/kdma.v9i3.11066

MacDonald, S. M., Rapalino, O., Sherry, N. A., Cohen, A. B., Ebb, D. H., Tarbell, N. J., \& Oakley, D. H. (2016). Case 32-2016. A 20-Year-Old Man with Gynecomastia. The New England Journal of Medicine, 375(16), 1567-1579. https://doi.org/10.1056/NEJMcpc1610098

Marli, Z. A. (2017). Transformasi paradigma manajeman keilmuan sekolah dasar menuju pendidikan dasar Islam. Fikrotuna: Jurnal Pendidikan Dan Manajemen Islam, 6(2), 553-565. https://doi.org/10.32806/jf.v6i2.3101

Mauluah, L., \& Marsigit, M. (2019). Ethnomathematics for elementary student: Exploration the learning resources at kraton Yogyakarta. International Journal of Scientific and Technology Research, 8(7), 776-780. Retrieved from http://www.ijstr.org/finalprint/july2019/Ethnomathematics-For-Elementary-Student-Exploration-The-LearningResources-At-Kraton-Yogyakarta.pdf

Miles, M. B., \& Huberman, A. M. (2009). Qualitative data analysis: An expanded sourcebook (2nd ed.). Retrieved from https://books.google.co.id/books?hl=id\&lr=\&id=U4lU_wJ5QEC\&oi=fnd\&pg=PA10\&dq=Qualitative+data+analysis+Miles\&ots=kFTH2HVZ1T\&si $\mathrm{g}=\mathrm{ctEW} \_F y 8$ VcHJaSI16_m2hLHAKA\&redir_esc=y\#v=onepage $\& \mathrm{q}=\mathrm{Qualitative}$ data analysis Miles\&f $=$ false

Putra, R. Y., Wijayanto, Z., \& Widodo, S. A. (2020). Etnomatematika: Masjid Soko Tunggal dalam pembelajaran geometri 2D. Jurnal Riset Pendidikan Dan Inovasi Pembelajaran Matematika (JRPIPM), 4(1), 10-22. https://doi.org/10.26740/jrpipm.v4n1.p10-22

Putri, L. I. (2017). Eksplorasi etnomatematika kesenian rebana sebagai sumber belajar matematika 
pada jenjang MI. Jurnal Ilmiah Pendidikan Dasar, 4(1), 21-31. https://doi.org/10.30659/pendas.4.1.\%25p

Rohaeti, E. E. (2011). Transformasi budaya melalui pembelajaran matematika bermakna di sekolah. Jurnal Pengajaran MIPA, 16(1), 139. https://doi.org/10.18269/jpmipa.v16i1.274

Rohayati, S., Karno, K., \& Chomariyah, W. I. (2017). Identifikasi etnomatematika Pada Masjid Agung di Yogyakarta. Prosiding Sempoa: Seminar Nasional, Pameran Alat Peraga, Dan Olimpiade Matematika, 1-8. Retrieved from http://hdl.handle.net/11617/8751

Sirate, F. S. (2012). Implementasi etnomatematika dalam pembelajaran matematika pada jenjang pendidikan sekolah dasar. Lentera Pendidikan: Jurnal Ilmu Tarbiyah Dan Keguruan, 15(1), 41-54. https://doi.org/10.24252/lp.2012v15n1a4

Son, A. L. (2017). Study ethnomatematics: Pengungkapan konsep matematika dan karakter siswa pada permainan kelereng masyarakat Suku Dawan. Journal of Medives: Journal of Mathematics Education IKIP Veteran Semarang, 1(2), 100-110.

Sugiyono, S. (2013). Metode penelitian pendidikan: Pendekatan kuantitatif, kualitatif, dan $R \& D$ (17th ed.). Bandung: Alfabeta.

Sunardi, S., \& Yudianto, E. (2016). Antisipasi siswa level analisis dalam menyelesaikan masalah geometri. AdMathEdu: Jurnal Ilmiah Pendidikan Matematika, Ilmu Matematika Dan Matematika Terapan, 5(2), 203-216. https://doi.org/10.12928/admathedu.v5i2.4776

Sunardi, S., Yudianto, E., Susanto, S., Kurniati, D., Cahyo, R. D., \& Subanji, S. (2019). Anxiety of students in visualization, analysis, and informal deduction levels to solve geometry problems. International Journal of Learning, Teaching and Educational Research, 18(4), 171-185. https://doi.org/10.26803/ijlter.18.4.10

Yudianto, E. (2015). Profil antisipasi siswa SMA dalam memecahkan masalah integral. Kreano: Jurnal Matematika Kreatif-Inovatif, 6(1), 21-25. https://doi.org/10.15294/kreano.v6i1.4472

Zayyadi, M. (2017). Eksplorasi etnomatematika pada batik Madura. Sigma, 2(2), 35-40. https://doi.org/10.0324/sigma.v2i2.124 